Article

\title{
Energy Conservation Potential Assessment Method for Table Grapes Supply Chain
}

\author{
Xinqing Xiao ${ }^{1,2}$, Xu Zhang ${ }^{1,2}$, Zetian Fu ${ }^{1,2}$, Weisong Mu ${ }^{1,2}$ and Xiaoshuan Zhang 1,2,* \\ 1 College of Engineering, China Agricultural University, Beijing 100083, China; xxqjd@cau.edu.cn (X.X.); \\ zhxu@cau.edu.cn (X.Z.); fzt@cau.edu.cn (Z.F.); wsmu@cau.edu.cn (W.M.) \\ 2 Beijing Laboratory of Food Quality and Safety, Beijing 100083, China \\ * Correspondence: zhxshuan@cau.edu.cn
}

Received: 19 June 2018; Accepted: 9 August 2018; Published: 10 August 2018

\begin{abstract}
Energy consumption is one of the most crucial issues in the table grapes supply chain. However, the potential for energy conservation assessment is still limited because of the complexity of the process. The aim of this paper is to propose an energy conservation potential assessment method in order to increase energy consumption transparency and help managers take appropriate energy conservation measures to reduce the energy consumption in the table grapes supply chain. The conservation potential assessment in three kinds of the supply chain modes (the normal chain, the cold insulation chain and the cold chain), were realized by integrating the actual energy consumption investigated with the unified energy consumption per unit energy factor that represents the energy consumption throughout the entire product lifecycle. According to the comprehensive analysis of the energy consumption compared with the energy conservation potential in actual supply chain of table grapes, the proposed energy conservation potential assessment method could provide a unified method for evaluating the energy conservation potential in different supply chain mode of table grapes. The energy conversation potential in cold insulation chain, which was about 0.985 , was the highest and that in cold chain, which was about 0.935 , was the smallest. However, the cold chain was still the optimal supply chain for the table grapes because of the characteristics of the longest storage shelf life and the lowest quality decay, and the cold chain energy consumption would be further reduced by adopting the more advanced refrigeration and preservation technologies. The proposed energy conservation potential assessment method could be extended for other supply chain applications to evaluate their own energy conservation potential, and thus, reduce their energy consumption.
\end{abstract}

Keywords: table grapes; energy conservation potential; energy consumption; energy factor; supply chain

\section{Introduction}

Energy consumption is one of the most crucial issues in the massive application of the table grapes supply chain [1]. In recent years, the table grapes supply chain has been developed rapidly with the swift increase in the table grapes production and consumer demand [2-4]. The massive energy consumption has been also increased, owing to the energy-intensive characteristic of the table grapes supply chain [5-7]. However, the energy consumption in the supply chain, for example, the electricity, the petroleum and the natural gas, are part of the non-renewable energy resources [8-10]. Therefore, it is necessary and important to synthetically assess the energy consumption and energy conservation potential in table grapes supply chain.

There are mainly three kinds of table grapes supply chain modes that are applied widely. They are the normal chain, the cold insulation chain and the cold chain. The normal chain of the table grapes, which is most and widely used, is mainly applied in short distance transportation, and the 
table grapes are all transported at the ambient environment in the chain [11-13]. The cold insulation chain, which is applied in medium distance transportation, are fully pre-cooled and stored at the low temperature by refrigeration method, and then transported to the market with the method of the cold insulation such as the quilt covering method [14]. The temperature in the cold insulation transportation increases slowly and the quality of the table grapes also decays slowly [15]. The cold chain, which is used for long-distance transportation, are also fully pre-cooled and stored at the low temperature by refrigeration method, and then refrigeration transported to the market [16]. The temperature is kept at a low temperature with the refrigeration method all the time [17]. However, the challenging issue for the energy conservation potential assessment of the different supply chain mode still exists, because the different supply chain mode has a different process and cost to guarantee the quality and safety of the table grapes. The more the process in the supply chain, the more devices are needed, thus contributing towards more energy consumption [18,19].

Currently, various studies about energy consumption and conservation potential in different energy-intensive supply chains have been reported. Chen et al. [20] have reported the energy conservation and optimization for the shale gas supply chain planning based on the life cycle assessment. Shen et al. [21] discussed the low carbon supply chain practices in China's textile industry by evaluating the energy consumption in actual supply chain, and finally made the optimal decisions of the supply chain. McBrien et al. [22] have analyzed the energy conservation potential in a typical steel supply chain by the integrated heat recovery method. Wang and Rutherford [23] have assessed the energy consumption and conservation potential in natural gas supply chain by the liquefied natural gas carriers. Vanek and Sun [24] explored the energy conservation potential for the temperature controlled perishable food supply chain, from crop to packaged product to consumer, by integrating the life cycle energy consumption model. However, most of these studies are focused on the single or typical process of the supply chain, and the unified energy conservation assessment method is needed to be applied to the different supply chain modes of table grapes.

Energy consumption per unit energy factor method, which is a scientific and reasonable energy consumption evaluation index to represent the total energy consumption of product per kilogram processed and the average energy conservation potential of the product throughout its entire lifecycle, provides a unified way for the different process of the industries [25-27]. For example, Zhang and Li [28] have calculated and estimated the energy consumption and energy conservation potential of the product lifecycle, from cradle to grave, based on the energy factor method. Feng et al. [29] and Xie [30] have assessed the energy consumption and energy conservation potential in the refinery industry by adopting the energy consumption per unit energy factor method, and the evaluation results showed that the method could effectively represent the energy conservation potential of the process in refinery industry.

The main objective of this study is to propose an energy conservation potential assessment method for the supply chain management of table grapes. The energy consumption and conservation potential assessment in three kinds of supply chain mode, which are the normal chain, the cold insulation chain and the cold chain, were realized by integrating the actual energy consumption investigated with the unified energy consumption per unit energy factor. The energy consumption analysis in the normal chain, the cold insulation chain and the cold chain, the energy consumption comparison and the energy conservation potential in table grapes supply chain were comprehensively evaluated in actual supply chain of table grapes. The proposed energy conservation potential assessment method could provide a unified method for evaluating the energy conservation potential in different supply chain mode of table grapes, increase the energy consumption transparency, and finally help the manager take the appropriate energy conservation measures to reduce the energy consumption in different supply chain mode.

The rest of the paper is organized as follows. The energy conservation potential materials and methods are described in Section 2. The evaluation results of the energy conservation potential method are discussed in Section 3. Conclusions and future work are presented in Section 4. 


\section{Materials and Methods}

This section illustrates the materials and methods for the research in more detail, which includes the properties of the table grapes supply chain investigated, the energy calculation method for the energy consumption calculation, the energy consumption assessment method, and the experimental scheme for the actual supply chain energy consumption assessment.

\subsection{Properties of the Tale Grapes Supply Chain Investigated}

To understand more about the properties and energy consumption of the table grapes supply chain, the field observation and investigation method was conducted in China in 2016. Three kinds of table grapes supply chain were classified according to the different transportation distance. They are the normal chain, cold insulation chain and the cold chain. The normal chain of table grapes is most and widely used for short distance transportation with the ambient environment. The cold insulation chain is applied in the medium distance transportation with the low temperature in cold insulation method, and the cold chain is used for the long-distance transportation with the low temperature in refrigeration method all the time. The normal chain was conducted from the Hebei province to Beijing city. The cold insulation chain was chosen from Xingjiang uygur autonomous region to Shandong province and the cold chain was from Xingjiang uygur autonomous region to Guangzhou city. The workflow of the table grapes supply chain is demonstrated in Figure 1.

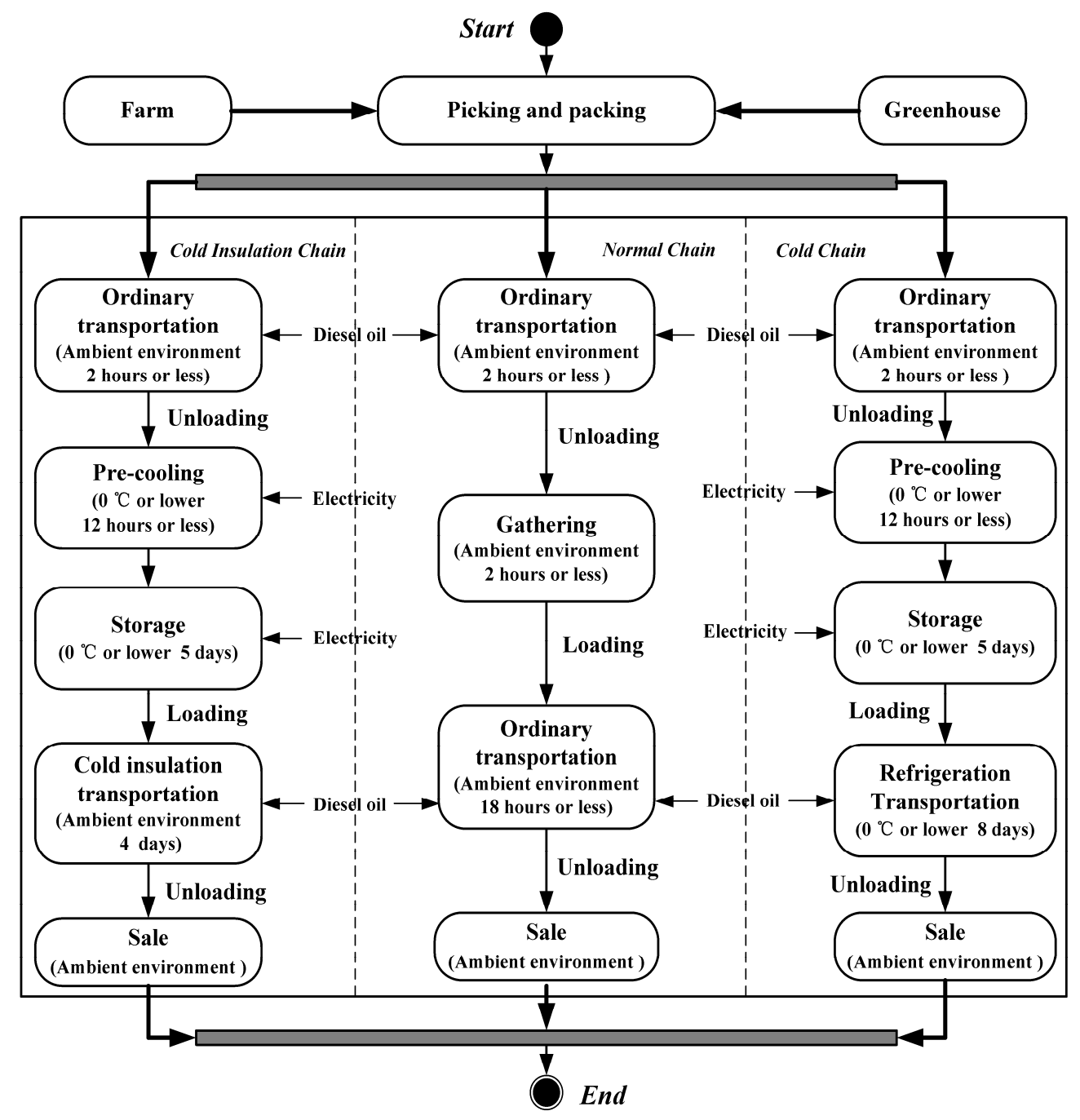

Figure 1. The workflow of table grapes supply chain. 
As shown in Figure 1, the first step for all the table grapes supply chain was picking and packing at the farm or the greenhouse, and then ordinarily transported to the pre-cooling and storage in the cold storage for the cold insulation chain and the cold chain, and to the gathering in the distribution center for the normal chain. Finally, the stored table grapes were cold insulation and refrigeration transported to the market for sale in cold insulation and cold chain, and the gathered table grapes were ordinarily transported to the market for sale in normal chain.

The energy in the pre-cooling and storage process of the cold insulation and cold chain are mainly consumed from the electricity, and the energy in the transportation process of all the supply chain, which includes the ordinary transportation from the farm or the greenhouse to cold storage or distribution center and the cold storage or distribution center to the market, are mainly consumed from the diesel oil of the truck.

However, the energy consumption in the different supply chains is not comparable and cannot comprehensively evaluate the energy consumption level and energy conservation potential in the table grapes supply chains, because of the complex composition of the supply chain and the different kinds of energy source in different phases. It is important to assess the energy consumption in different phases and explore the energy conservation potential in table grapes supply chain.

\subsection{Energy Consumption Calculation Method}

The energy calculation method is applied to calculate the energy consumption in the process of the pre-cooling, storage and transportation according to the actual supply chain investigation.

The pre-cooling energy in cold insulation and cold chain consist of the power of the pre-cooling equipment and the pre-cooling time of the table grapes in cold storage. The pre-cooling energy $Q_{P}$ is calculated as demonstrated in Equation (1).

$$
Q_{P}=P_{p} t_{p}
$$

where the $P_{p}$ is the power of the pre-cooling equipment and the $t_{p}$ is the pre-cooling time of the table grapes in cold storage.

The storage energy in the cold insulation and cold chain are composed of the power of the refrigeration plant and the refrigeration time of the table grapes in cold storage. The storage energy $Q_{S}$ is calculated as illustrated in Equation (2).

$$
Q_{S}=P_{S} t_{S}
$$

where the $P_{s}$ is the power of the refrigeration plant and the $t_{s}$ is the refrigeration time of the table grapes in cold storage.

The transportation is the critical and essential process in the supply chain. The energy in cold insulation and normal chain transportation are mainly the driving energy, while the energy in cold chain transportation is mainly composed of the driving energy and the refrigeration energy.

The driving energy is related to the driving engine power and transportation time. The refrigeration energy is related to the power of the refrigeration plant and the refrigeration time in refrigeration transportation. The transportation energy $Q_{T}$ is calculated as described in Equations (3)-(5).

$$
\begin{gathered}
Q_{T}=Q_{d}+Q_{r} \\
Q_{d}=P_{d} t_{d} \\
Q_{r}=P_{r} t_{r}
\end{gathered}
$$

where the $Q_{d}$ is the driving energy, the $Q_{r}$ is the refrigeration energy in refrigeration transportation, the $P_{d}$ is the driving engine power of the truck, the $t_{d}$ is the total transportation time, the $P_{r}$ 
is the power of the refrigeration plant and the $t_{r}$ is the refrigeration time of the table grapes in refrigeration transportation.

\subsection{Energy Conservation Potential Assessment Method}

The energy consumption per unit energy factor [28-30], which is a scientific and reasonable energy consumption evaluation index to represent the total energy consumption of product per kilogram processed and the average energy conservation potential of the supply chain, was applied to assess the comprehensive energy consumption of table grapes supply chain through its entire lifecycle in various situations. The energy conservation potential of the product was higher if its value was also higher.

Assuming that the table grapes supply chain includes $n$ energy consumption phases, the number of the table grapes processed in the phases are $A_{1}, A_{2}, \cdots, A_{n}$, the actual energy consumption in the phases are $E_{1}, E_{2}, \cdots, E_{n}$ and the calculated energy consumption in the phases are $C_{1}, C_{2}, \cdots, C_{n}$, then the energy consumption per unit energy factor of table grapes supply chain $U$ is defined as Equation (6).

$$
U=\frac{\left(\sum_{i=1}^{n} A_{i} E_{i}\right) /\left(A_{1} E_{1}\right)}{\left(\sum_{i=1}^{n} A_{i} C_{i}\right) /\left(A_{1} C_{1}\right)}
$$

where the $\left(\sum_{i=1}^{n} A_{i} C_{i}\right) /\left(A_{1} C_{1}\right)$ is the energy factor that represents the complexity of table grapes supply chain, the $\sum_{i=1}^{n} A_{i} E_{i}$ represents the calculated theoretical energy consumption of table grapes supply chain, and the $\sum_{i=1}^{n} A_{i} C_{i}$ represents the actual energy consumption.

\subsection{Experimental Scheme}

The Kyoho table grapes (Vitis vinifera L. $\times$ V. labrusca L. cv. Kyoho) were chosen as the experimental material. Three experiments were performed to the table grapes supply chain of the normal chain, cold insulation and cold chain. The experimental scheme of the table grapes supply chain is demonstrated in Figure 2.

- Experiment I was conducted for the normal chain of table grapes for investigating the energy consumption in the process of the ordinary transportation.

- Experiment II was performed in relation to the cold insulation chain of table grapes for calculating the energy consumption in the process of the pre-cooling, the storage and the cold insulation transportation.

- Experiment III was conducted for the cold chain of table grapes for evaluating the energy consumption in the process of the pre-cooling, the storage and the refrigeration transportation. 


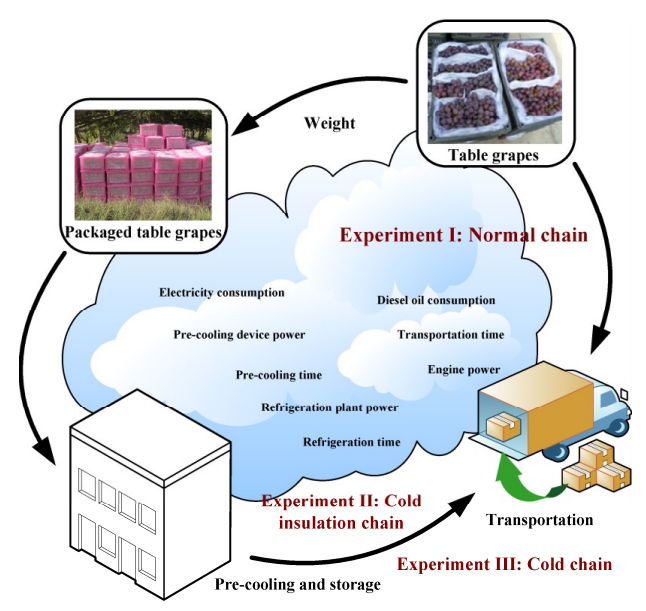

Figure 2. The experimental scheme of table grapes supply chain.

For Experiment I, the table grapes were picked and packed in a greenhouse from Hebei province, and ordinarily transported to Beijing city. The table grapes were manually harvested at complete ripeness without machinery and pest damage. The diesel oil consumption, which includes the ordinary transportation from the greenhouse to the distribution center and from the distribution center to Beijing city, was evaluated.

For Experiment II, the table grapes, which were the same as the harvest of Experiment I, were picked and packed in a farm from Xingiiang uygur autonomous region, and finally cold insulation transported to Shandong province. The electricity consumption in pre-cooling and storage, and the diesel oil consumption which includes the ordinary transportation from the farm to the cold storage and the cold insulation transportation from the cold storage to Guangzhou city, were assessed.

For Experiment III, which were the same as Experiment II, the table grapes were refrigeration transported from the Xingjiang uygur autonomous region to Guangzhou city. The electricity consumption in pre-cooling and storage, and the diesel oil consumption, which includes the ordinary transportation from the farm to the cold storage and the refrigeration transportation from the cold storage to Guangzhou city, were evaluated.

The table grapes were weighed after the package by using the platform scale (TGT-1000B, Shanghai, China). The electricity consumption was measured by recording the power of the pre-cooling and refrigeration devices and the pre-cooling and the refrigeration time in cold storage. The diesel oil consumption was assessed by recording to the engine power, the transportation distance and the average velocity in cold insulation chain and the cold chain, and also the refrigeration plant power and the refrigeration time in the process of refrigeration transportation in cold chain.

\subsection{Statistical Analysis}

The energy consumption in table grapes supply chain was analyzed by using energy consumption loss rate [31]. The definition is demonstrated as Equation (7).

$$
\text { loss rate }=\left|\frac{E_{i}-C_{i}}{E_{i}}\right| \times 100 \%, i=1,2, \cdots, n
$$

In addition, the energy consumption in the table grapes supply chain was expressed by mega joule (MJ) [32]. The electricity consumption of $1 \mathrm{kWh}$ was about $3600 \mathrm{~kJ}$ [33]. The diesel oil consumption of $1 \mathrm{~L}$ was about $0.85 \mathrm{~kg}$ [34], and the diesel oil consumption of $1 \mathrm{~kg}$ was about 42,652 kJ [35].

The data statistical and processing were performed by using Matlab R2012b software (MathWorks Incorporated, Massachusetts Natick, MN, USA) and Microsoft Office Excel 2016 software (Microsoft Corporation, Redmond Washington, RW, USA). 


\section{Results}

Comparison results of the energy consumption and the energy conservation potential in the table grapes supply of the normal chain, cold insulation chain and cold chain are analyzed and assessed in this section according to the experimental scheme.

\subsection{Energy Consumption Analysis in Normal Chain}

As illustrated in Experiment I, the table grapes in normal chain were transported from Hebei province to Beijing city in China. The total weight of the table grapes was about $10,000 \mathrm{~kg}$, and the time of the whole chain was about $10 \mathrm{~h}$. The energy consumption in normal chain was mainly from the transportation process.

The general small truck, whose engine power was about $22 \mathrm{~kW}$, was employed to the ordinary transportation from the greenhouse to the distribution center. The one-way transportation distance was about $3 \mathrm{~km}$. The total transportation frequency was about 10, and the average weight was about $1000 \mathrm{~kg}$ every time. The total transportation time was about $5 \mathrm{~h}$. The total diesel oil consumption was about $13 \mathrm{~L}$ in the actual transportation.

The general medium truck, whose engine power was about $95 \mathrm{~kW}$, was applied to the ordinary transportation from the distribution center to the market. The transportation distance was about $202 \mathrm{~km}$, and the average transportation time was about $5 \mathrm{~h}$. The total diesel oil consumption was about $56 \mathrm{~L}$ in actual transportation.

The comparison of the calculated and actual energy consumption in normal chain is demonstrated in Figure 3. The calculated energy consumption in the ordinary transportation from the greenhouse to the distribution center was about $396 \mathrm{MJ}$, and the calculated energy consumption in the ordinary transportation from the distribution center to the market was about $1710 \mathrm{MJ}$. The actual energy consumption in the ordinary transportation from the greenhouse to the distribution center was about 505.1 MJ, and the actual energy consumption in the ordinary transportation from the distribution center to the market was about 2030.235 MJ.

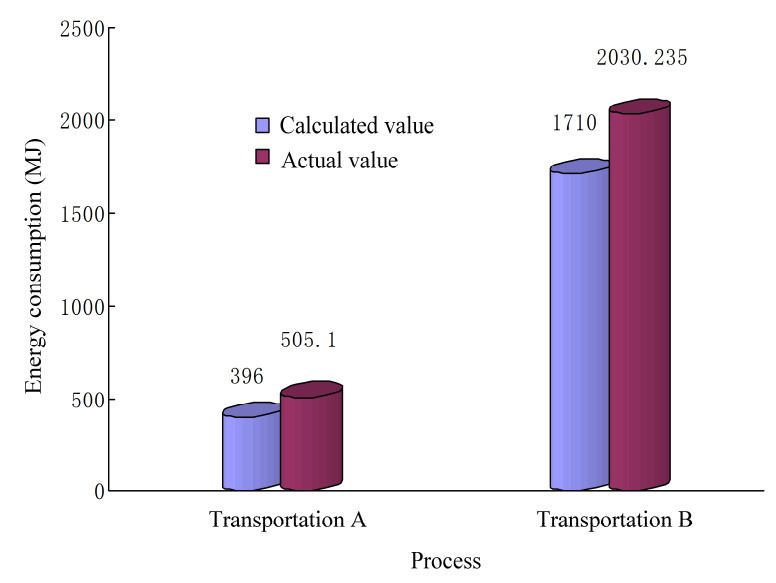

Figure 3. Comparison of the calculated and actual energy consumption in normal chain.

The loss rate of the calculated and actual energy consumption in normal chain was described in Table 1 . The loss rate of the energy consumption in the ordinary transportation from the greenhouse to the distribution center (Transportation A) was about $21.59 \%$, and the loss rate of the energy consumption in the ordinary transportation from the distribution center to the market (Transportation B) was about $15.78 \%$. The total loss rate of the energy consumption in normal chain was about $16.93 \%$. 
Table 1. The loss rate of the calculated and actual energy consumption in normal chain.

\begin{tabular}{ccc}
\hline Process & Loss Rate (\%) & Total Loss Rate (\%) \\
\hline Transportation A & 21.59 & 16.93 \\
Transportation B & 15.78 & \\
\hline
\end{tabular}

\subsection{Energy Consumption Analysis in Cold Insulation Chain}

As illustrated in Experiment II, the table grapes in cold insulation chain were transported from Xingjiang uygur autonomous region to Shandong province in China. The total weight of the table grapes transported was about $26,000 \mathrm{~kg}$, and the time of the whole chain was about 8 days. The energy consumption in cold insulation chain was mainly from the process of pre-cooling, storage and transportation.

The general small truck, the same as Experiment I, was employed to the ordinary transportation from the farm to the cold storage. The one-way transportation distance was about $5 \mathrm{~km}$. The total transportation frequency was about 20, and the average weight was about $1300 \mathrm{~kg}$ every time. The total transportation time was about $39.6 \mathrm{~h}$. The total diesel oil consumption was about $108 \mathrm{~L}$ in actual transportation.

The forced air-cooling method, which forces the cool air flowing in the cold storage in cycle, was applied to the pre-cooling and storage. The power of the refrigeration plant in pre-cooling was about $15 \mathrm{~kW}$, and the power of the refrigeration plant in storage was about $4 \mathrm{~kW}$. The pre-cooling time was about $24 \mathrm{~h}$, and the storage refrigeration time in storage was about $72 \mathrm{~h}$.

The general heavy truck, whose engine power was about $257 \mathrm{~kW}$, was applied to the cold insulation chain transportation from the cold storage to the market. The transportation distance was about $3689 \mathrm{~km}$. The average transportation time was about 4 days, and the actual driving time was about $58 \mathrm{~h}$. The total diesel oil consumption was about $1642 \mathrm{~L}$ in actual transportation.

The comparison of the calculated and actual energy consumption in cold insulation chain is illustrated in Figure 4. The calculated energy consumption in the process of the ordinary transportation, pre-cooling, storage, and cold insulation transportation was about 3136.32 MJ, 1296 MJ, 1036.8 MJ and $53,661.6 \mathrm{MJ}$. The actual energy consumption in the ordinary transportation, pre-cooling, storage and cold insulation chain was about 3915.453 MJ, 1332 MJ, 1134 MJ and 66,332.39 MJ.

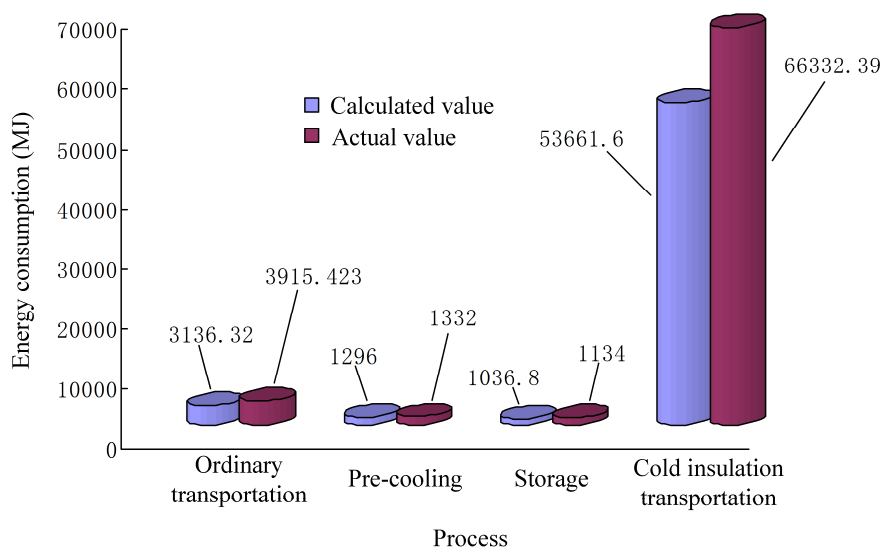

Figure 4. Comparison of the calculated and actual energy consumption in cold insulation chain.

The loss rate of the calculated and actual energy consumption in cold insulation chain is presented in Table 2. The loss rate of the energy consumption in the ordinary transportation, pre-cooling, storage and cold insulation transportation was about $19.9 \%, 2.7 \%, 8.57 \%$ and $19.11 \%$. The total loss rate of the energy consumption in cold insulation chain was about $18.87 \%$. 
Table 2. The loss rate of the calculated and actual energy consumption in cold insulation chain.

\begin{tabular}{ccc}
\hline Process & Loss Rate (\%) & Total loss Rate (\%) \\
\hline Ordinary transportation & 19.9 & \\
Pre-cooling & 2.7 & 18.87 \\
Storage & 8.57 & \\
Cold insulation transportation & 19.11 & \\
\hline
\end{tabular}

\subsection{Energy Consumption Analysis in Cold Chain}

As illustrated in Experiment III, the table grapes in cold chain were transported from Xingjiang uygur autonomous region to Guangzhou city in China. The total weight of the table grapes transported was about $30,000 \mathrm{~kg}$, and the time of the whole chain was about 10 days. The energy consumption in cold chain was mainly from the process of pre-cooling, storage and transportation.

The general small truck, the same as the experiment I, was employed to the ordinary transportation from the farm to the cold storage. The one-way transportation distance was about $6 \mathrm{~km}$. The total transportation frequency was also about 20 , and the average weight was about $1500 \mathrm{~kg}$ every time. The total transportation time was about $33.6 \mathrm{~h}$. The total diesel oil consumption was about $97 \mathrm{~L}$ in actual transportation.

The pressure cooling method, which forced the cool air flowing through the different pressure on both sides of the packaged table grapes in the cold storage, was applied to the pre-cooling and the storage. The power of the refrigeration plant in pre-cooling was about $56 \mathrm{~kW}$, and the power of the refrigeration plant in storage was also about $2 \mathrm{~kW}$. The pre-cooling time was about $15 \mathrm{~h}$, and the storage refrigeration time in storage was about $113 \mathrm{~h}$.

The heavy refrigeration truck, whose engine power was about $275 \mathrm{~kW}$, was used to the refrigeration transportation from the cold storage to the market. The transportation distance was about $4780 \mathrm{~km}$. The average transportation time was about 5 days, and the actual driving time was about $95 \mathrm{~h}$. The total diesel oil consumption was about $3073 \mathrm{~L}$ in actual transportation.

The comparison of the calculated and actual energy consumption in cold chain is illustrated in Figure 5. The calculated energy consumption in the ordinary transportation, pre-cooling, storage and refrigeration transportation was about 2661.12 MJ, 3024 MJ, 813.6 MJ and 94,050 MJ, and the actual energy consumption in the ordinary transportation, pre-cooling, storage and cold insulation chain was about 3516.657 MJ, 4506.48 MJ, 1382.400 MJ and 111,403.977 MJ.

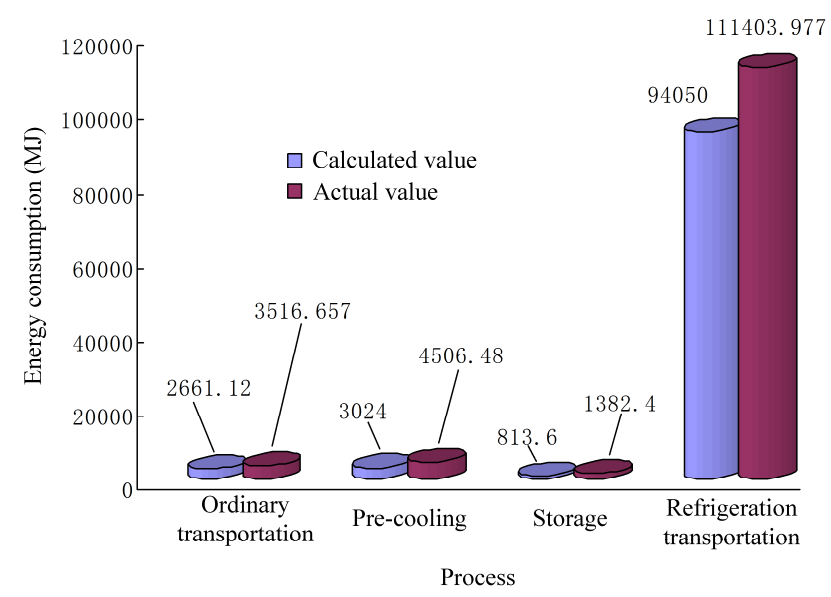

Figure 5. Comparison of the calculated and actual energy consumption in cold chain.

The loss rate of the calculated and actual energy consumption in cold chain was presented in Table 3. The loss rate of the energy consumption in the ordinary transportation, pre-cooling, storage 
and refrigeration transportation was about $24.33 \%, 32.9 \%, 41.15 \%$ and $15.58 \%$. The total loss rate of the energy consumption in cold chain was about $15.21 \%$.

Table 3. The loss rate of the calculated and actual energy consumption in cold chain.

\begin{tabular}{ccc}
\hline Process & Loss Rate (\%) & Total Loss Rate (\%) \\
\hline Ordinary transportation & 24.33 & \\
Pre-cooling & 32.9 & \\
Storage & 41.15 & 15.21 \\
Refrigeration transportation & 15.58 & \\
\hline
\end{tabular}

\subsection{Energy Consumption Comparison Analysis in Table Grapes Supply Chain}

The different supply chain has the different process and cost to guarantee the quality and safety of the table grapes. The total energy consumption in the normal chain, cold insulation chain and cold chain is demonstrated in Figure 6. The actual and calculated energy consumption in the cold chain was about 133,251.114 MJ and 107,871.12 MJ, and the actual and calculated energy consumption in the normal chain was about $2535.335 \mathrm{MJ}$ and $2106 \mathrm{MJ}$.

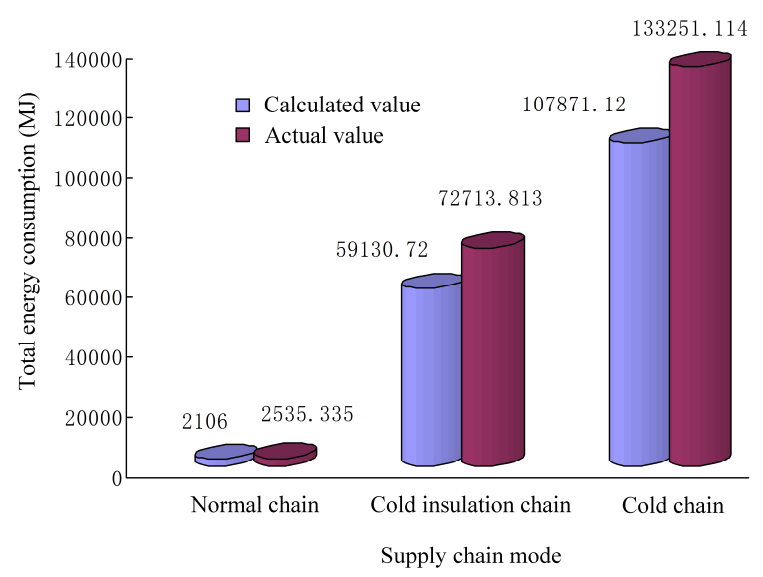

Figure 6. Comparison of the total energy consumption in table grapes supply chain.

\subsection{Energy Conversation Potential Assessment in Table Grapes Supply Chain}

The energy conservation potential in the normal chain, cold insulation chain and cold chain were assessed by combining with the energy consumption analysis. The energy factor in different supply chain was described in Figure 7 and the energy consumption per unit energy factor in different supply chain was illustrated in Figure 8.

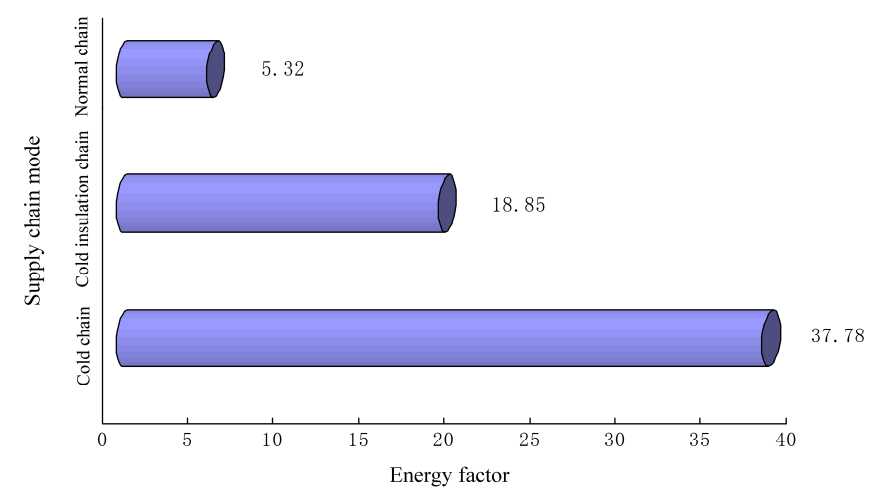

Figure 7. The energy factor in different supply chain. 


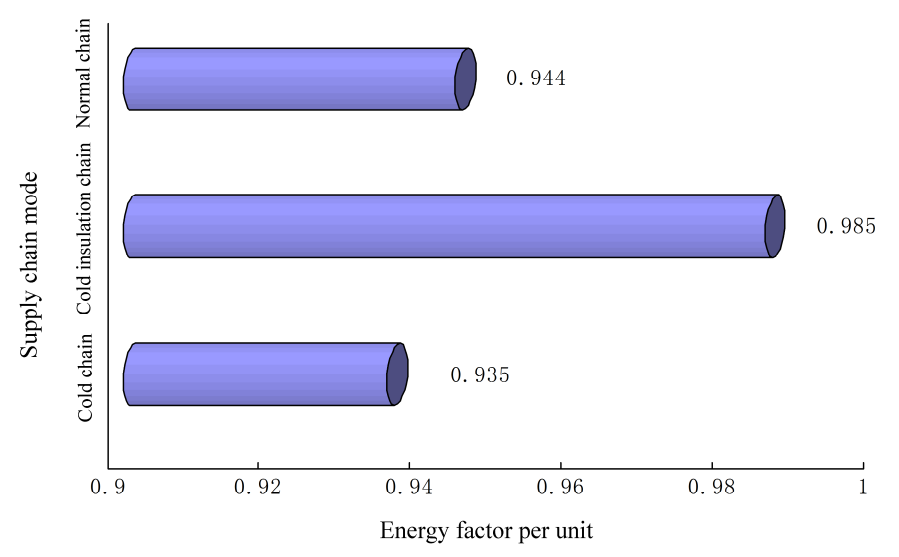

Figure 8. The energy consumption per unit energy factor in different supply chain.

As presented in Figures 7 and 8, the energy factor in the normal chain was about 5.32 and the energy consumption per unit energy factor was about 0.944 . The energy factor in the cold insulation chain was about 18.85 and the energy consumption per unit energy factor was about 0.985 . The energy conversation potential in cold insulation chain was highest among the table grapes supply chain mode. The energy factor in the cold chain was about 37.78 and the energy consumption per unit energy factor was about 0.935 . The energy conversation potential in cold chain was smallest.

\section{Discussion}

According to the energy consumption analysis of the table grapes supply chain, the energy consumption in the cold chain was highest because of the complex refrigeration process and long-distance transportation in the cold chain, and the energy consumption in the normal chain was lowest because of the simple and short distance transportation.

The different supply chain has the different process and cost to guarantee the quality and safety of the table grapes. The more the processes were in supply chain, the more devices were needed, thus making the more energy consumption. The cold chain should keep the table grapes be stored at a low temperature all the time by the refrigeration plants in the whole chain, while the cold insulation chain was just refrigeration storage in the pre-cooling and storage, and the normal chain was transported in the ambient environment.

According to the energy consumption analysis results in the table grapes supply chain, the energy consumption in actual supply chain were all higher than that the calculated value. The results may be due to that the external devices or operation energy consumption in supply chain. For example, the lighting, the loading and unloading operation energy consumption in pre-cooling and storage, the air conditioner used in summer day in the truck, and also the heavy traffic in the actual transportation [36].

As presented in Figures 7 and 8, the energy factor in the normal chain was lower than that in the cold insulation chain and cold chain, while the energy consumption per unit energy factor was higher than that in the cold chain and lower than that in the cold insulation chain. The reason may due to the simple process and short distance transportation in the normal chain. The energy conversation potential in normal chain was relatively small.

The energy factor in the cold insulation chain was lower than that in the cold chain and higher than that in normal chain, while the energy consumption per unit energy factor was highest. The energy conversation potential in cold insulation chain was highest. The reason may due to that there was also no any energy conservation measures were applied in the cold insulation chain, and also the old truck was used in the investigated ordinary and cold insulation transportation [29-31].

The energy factor in the cold chain was highest, while the energy consumption per unit energy factor was lowest. The energy conversation potential in cold chain was smallest. The reason may 
due to the complex refrigeration process and long-distance transportation, and also the advanced refrigeration measures, such as the refrigeration plant and truck, were applied in cold chain.

However, the cold chain was still the optimal supply chain for the table grapes because of the characteristics of the longest storage shelf life and the lowest quality decay even though the cold chain has a smallest conservation potential according to the result of the energy conversation potential assessment. The energy consumption in the cold chain would also be further reduced by adopting the more advanced refrigeration and preservation technologies [37-39].

The results show that the energy conservation potential assessment method could provide a unified method for evaluating the energy conservation potential in different supply chain mode of table grapes, increase the energy transparency in table grapes supply chain, and finally help the manager take the appropriate energy conservation measures to reduce the energy consumption in different supply chain mode.

\section{Conclusions}

This paper proposes an energy conservation potential assessment method for the supply chain management of table grapes in order to increase the energy consumption transparency and help the manager take the appropriate energy conservation measures to reduce the energy consumption. The energy consumption and conservation potential assessment in three kinds of the supply chain mode, which are the normal chain, the cold insulation chain and the cold chain, were realized by integrating the actual energy consumption investigated with the unified energy consumption per unit energy factor. The energy consumption comparison and the energy conservation potential in actual table grapes supply chain were comprehensively analyzed and assessed.

The different supply chain has the different process and cost to guarantee the quality and safety of the table grapes. The more the processes were in supply chain, the more devices were needed, thus making the more energy consumption. The energy consumption in the cold chain, whose actual value was about 133,251.114 MJ and calculated value was about 107,871.12 MJ, was highest, and the energy consumption in the normal chain, whose actual value was about $2535.335 \mathrm{MJ}$ and calculated value was about $2106 \mathrm{MJ}$, was lowest. The total loss rate of the energy consumption in normal chain, cold insulation chain and cold chain was about $16.93 \%, 18.87 \%$ and $15.21 \%$, respectively.

The energy conversation potential in cold insulation chain, which was about 0.985 , was the highest and that in cold chain, which was about 0.935 , was the smallest. However, the cold chain was still the optimal supply chain for the table grapes because of the characteristics of the longest storage shelf life and the lowest quality decay, and the cold chain energy consumption would be further reduced by adopting the more advanced refrigeration and preservation technologies.

In this study, the comprehensive analysis of the energy consumption comparison and the energy conservation potential in actual table grapes supply chain indicate that the proposed energy conservation potential assessment method could provide a unified method for evaluating the energy conservation potential in different supply chain mode of table grapes.

The proposed energy conservation potential assessment method could be extended for other supply chain application. It is also possible to integrate the others energy consumption and conservation potential assessment methods such as the life cycle energy consumption into the energy conservation potential for supply chain management.

Author Contributions: Conceptualization and Validation, X.X. and X.Z. (Xiaoshuan Zhang); Methodology, X.X.; Investigation, X.Z. (Xu Zhang) and W.M.; Writing-Original Draft Preparation and Writing-Review \& Editing, X.X. and X.Z. (Xu Zhang); X.X.; Supervision, Z.F. and X.Z. (Xiaoshuan Zhang); Project Administration and Funding Acquisition, X.Z. (Xiaoshuan Zhang).

Funding: This research is supported by the National Key R\&D Program of China (2017YFE0111200) from Ministry of Science and Technology, the China Agriculture Research System (CARS-30) from Ministry of Agriculture of China and the postdoctoral project funded by China Postdoctoral Science Foundation (2018M630223, 20181T110160) and the opening project from key laboratory of agricultural informatization standardization of Ministry of Agriculture and Rural Affairs (China Agricultural University) (AIS2018-02). 
Conflicts of Interest: The authors declare no conflict of interest. The funders had no role in the design of the study; in the collection, analyses, or interpretation of data; in the writing of the manuscript, and in the decision to publish the results.

\section{References}

1. Deng, L.; Wang, R.; Dong, T.; Feng, J.; Mu, W. Assessing the table grape supply chain performance in China-A value chain analysis perspective. Br. Food J. 2016, 118, 1129-1145. [CrossRef]

2. Xiao, X.; Li, Z.; Matetic, M.; Bakaric, M.B.; Zhang, X. Energy-Efficient sensing method for table grapes cold chain management. J. Clean. Prod. 2017, 152, 77-87. [CrossRef]

3. Litskas, V.D.; Irakleous, T.; Tzortzakis, N.; Stavrinides, M.C. Determining the carbon footprint of indigenous and introduced grape varieties through Life Cycle Assessment using the island of Cyprus as a case study. J. Clean. Prod. 2017, 156, 418-425. [CrossRef]

4. Feliziani, E.; Romanazzi, G.; Smilanick, J.L. Application of low concentrations of ozone during the cold storage of table grapes. Postharvest Biol. Technol. 2014, 93, 38-48. [CrossRef]

5. Wang, X.; He, Q.; Matetic, M.; Jemric, T.; Zhang, X. Development and evaluation on a wireless multi-gas-sensors system for improving traceability and transparency of table grape cold chain. Comput. Electron. Agric. 2017, 135, 195-207. [CrossRef]

6. Kucukvar, M.; Samadi, H. Linking national food production to global supply chain impacts for the energy-climate challenge: The cases of the EU-27 and Turkey. J. Clean. Prod. 2015, 108, 395-408. [CrossRef]

7. Jin, M.; Granda-Marulanda, N.A.; Down, I. The impact of carbon policies on supply chain design and logistics of a major retailer. J. Clean. Prod. 2014, 85, 453-461. [CrossRef]

8. Cucchiella, F.; D'Adamo, I. Issue on supply chain of renewable energy. Energy Convers. Manag. 2013, 76, 774-780. [CrossRef]

9. Heidari, M.; Omid, M. Energy use patterns and econometric models of major greenhouse vegetable productions in Iran. Energy 2011, 36, 220-225. [CrossRef]

10. Beske, P.; Land, A.; Seuring, S. Sustainable supply chain management practices and dynamic capabilities in the food industry: A critical analysis of the literature. Int. J. Prod. Econ. 2014, 152, 131-143. [CrossRef]

11. Ma, C.; Xiao, X.; Zhu, Z.; Vlad, L.B.; Zhang, X. Contour Diagram-Based Evaluation on Logistics Stability of Table Grapes under Variable Temperature. J. Food Process. Eng. 2016, 39, 391-399. [CrossRef]

12. Xu, W.; Li, D.; Fu, Y.; Liu, Z.; Wang, Y.; Yu, X.; Shang, W. Extending the shelf life of Victoria table grapes by high permeability and fungicide packaging at room temperature. Packag. Technol. Sci. 2013, 26, 43-50. [CrossRef]

13. Lin, B.; Du, Y.; Liang, X.; Wang, X.; Wang, X.; Yang, J. Effect of chitosan coating on respiratory behavior and quality of stored litchi under ambient temperature. J. Food Eng. 2011, 102, 94-99. [CrossRef]

14. Huang, Y.; Wang, B.; Zhou, S.; Wu, J.; Lei, G.; Li, P. Sun, P. Modeling and experimental study on combination of foam and variable density multilayer insulation for cryogen storage. Energy 2017, 123, 487-498. [CrossRef]

15. Li, Y.-C.M.; Chen, Y.-H.A. Assessing the thermal performance of three cold energy storage materials with low eutectic temperature for food cold chain. Energy 2016, 115, 238-256. [CrossRef]

16. Xiao, X.; He, Q.; Li, Z.; Antoce, A.O.; Zhang, X. Improving traceability and transparency of table grapes cold chain logistics by integrating WSN and correlation analysis. Food Control 2017, 73, 1556-1563. [CrossRef]

17. Qi, L.; Xu, M.; Fu, Z.; Mira, T.; Zhang, X. C 2 SLDS: A WSN-based perishable food shelf-life prediction and LSFO strategy decision support system in cold chain logistics. Food Control 2014, 38, 19-29. [CrossRef]

18. Wang, X.; Cai, H.; Florig, H.K. Energy-Saving implications from supply chain improvement: An exploratory study on China's consumer goods retail system. Energy Policy 2016, 95, 411-420. [CrossRef]

19. Brandenburg, M.; Govindan, K.; Sarkis, J.; Seuring, S. Quantitative models for sustainable supply chain management: Developments and directions. Eur. J. Oper. Res. 2014, 233, 299-312. [CrossRef]

20. Chen, Y.; He, L.; Guan, Y.; Lu, H.; Li, J. Life cycle assessment of greenhouse gas emissions and water-energy optimization for shale gas supply chain planning based on multi-level approach: Case study in Barnett, Marcellus, Fayetteville, and Haynesville shales. Energy Convers. Manag. 2017, 134, 382-398. [CrossRef]

21. Shen, B.; Ding, X.; Chen, L.; Chan, H.L. Low carbon supply chain with energy consumption constraints: Case studies from China's textile industry and simple analytical model. Supply Chain Manag. Int. J. 2017, 22, 258-269. [CrossRef] 
22. McBrien, M.; Serrenho, A.C.; Allwood, J.M. Potential for energy savings by heat recovery in an integrated steel supply chain. Appl. Therm. Eng. 2016, 103, 592-606. [CrossRef]

23. Wang, H.; Rutherford, D. Assessment of Energy Consumption by Liquefied Natural Gas Carriers and Impact of Improving the Energy Efficiency on Natural Gas Supply Chain. Transp. Res. Rec. 2015, 40-47. [CrossRef]

24. Vanek, F.; Sun, Y. Transportation versus perishability in life cycle energy consumption: A case study of the temperature-controlled food product supply chain. Transp. Res. Part D Transp. Environ. 2008, 13, 383-391. [CrossRef]

25. Lin, B.; Xie, X. Energy conservation potential in China's petroleum refining industry: Evidence and policy implications. Energy Convers. Manag. 2015, 91, 377-386. [CrossRef]

26. Boharb, A.; Allouhi, A.; Saidur, R.; Kousksou, T.; Jamil, A. Energy conservation potential of an energy audit within the pulp and paper industry in Morocco. J. Clean. Prod. 2017, 149, 569-581. [CrossRef]

27. Wu, X.; Zhao, L.; Zhang, Y.; Zhao, L.; Zheng, C.; Gao, X.; Cen, K. Cost and potential of energy conservation and collaborative pollutant reduction in the iron and steel industry in China. Appl. Energy 2016, 184, 171-183. [CrossRef]

28. Zhang, H.C.; Li, H. An energy factor based systematic approach to energy-saving product design. CIRP Ann. Manuf. Technol. 2010, 59, 183-186. [CrossRef]

29. Feng, H.-Q.; Liu, D.-J.; Wang, Y.-C. Study on Gray Relation Theory Application in Energy consuming Evaluation of Refining Unit. Chem. Eng. Mach. 2013, 6, 713-718.

30. Xie, X. Establishment of evaluation index of complete energy consumption and application. Pet. Refin. Eng. 2012, 9, 49-53.

31. Finn, P.; Fitzpatrick, C.; Connolly, D.; Leahy, M.; Relihan, L. Facilitation of renewable electricity using price based appliance control in Ireland's electricity market. Energy 2011, 36, 2952-2960. [CrossRef]

32. Saad, A.; Das, T.; Rana, D.; Sharma, A.; Bhattacharyya, R.; Lal, K. Energy auditing of a maize-wheatgreengram cropping system under conventional and conservation agriculture in irrigated north-western Indo-Gangetic Plains. Energy 2016, 116, 293-305. [CrossRef]

33. Zackrisson, M.; Avellán, L.; Orlenius, J. Life cycle assessment of lithium-ion batteries for plug-in hybrid electric vehicles-Critical issues. J. Clean. Prod. 2010, 18, 1519-1529. [CrossRef]

34. Li, T.; Liu, Z.-C.; Zhang, H.-C.; Jiang, Q.-H. Environmental emissions and energy consumptions assessment of a diesel engine from the life cycle perspective. J. Clean. Prod. 2013, 53, 7-12. [CrossRef]

35. Feng, C.; Gao, X.; Tang, Y.; Zhang, Y. Comparative life cycle environmental assessment of flue gas desulphurization technologies in China. J. Clean. Prod. 2014, 68, 81-92. [CrossRef]

36. Powell, J.; González-Gil, A.; Palacin, R. Experimental assessment of the energy consumption of urban rail vehicles during stabling hours: Influence of ambient temperature. Appl. Therm. Eng. 2014, 66, 541-547. [CrossRef]

37. Evans, J.; Foster, A.; Huet, J.-M.; Reinholdt, L.; Fikiin, K.; Zilio, C.; Houska, M.; Landfeld, A.; Bond, C.; Scheurs, M.; et al. Specific energy consumption values for various refrigerated food cold stores. Energy Build. 2014, 74, 141-151. [CrossRef]

38. Nunes, J.; Neves, D.; Gaspar, P.D.; Silva, P.D.; Andrade, L.P. Predictive tool of energy performance of cold storage in agrifood industries: The Portuguese case study. Energy Convers. Manag. 2014, 88, 758-767. [CrossRef]

39. Kuo, J.-C.; Chen, M.-C. Developing an advanced multi-temperature joint distribution system for the food cold chain. Food Control 2010, 21, 559-566. [CrossRef]

(C) 2018 by the authors. Licensee MDPI, Basel, Switzerland. This article is an open access article distributed under the terms and conditions of the Creative Commons Attribution (CC BY) license (http:// creativecommons.org/licenses/by/4.0/). 